\title{
Lime stabilization of expansive soil from Sergipe - Brazil
}

\author{
Rafaella Leite $^{1, a}$, Rodrigo Cardoso ${ }^{1}$, Carlos Cardoso ${ }^{1}$, Erinaldo Cavalcante ${ }^{2}$ and Osvaldo de Freitas ${ }^{3}$

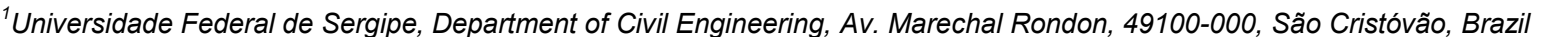

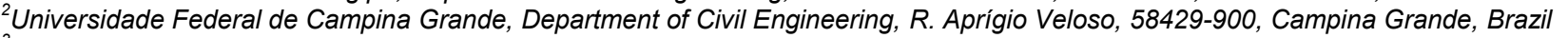

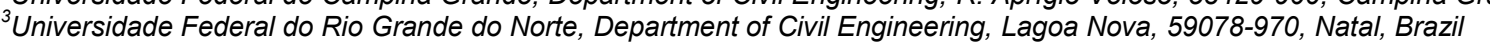

\begin{abstract}
Expansive soils are characterized by volumetric changes caused by variations in moisture. They can cause several damages to civil constructions, especially to lightweight structures, including cracks and fissures. Chemical stabilization through addition of lime is one of the most effective techniques used to treat this type of soil. Due to cationic exchanges, lime can significantly reduce swell potential. This research studied a disturbed sample of expansive soil collected in Nossa Senhora do Socorro - Sergipe, Brazil, through the following laboratory tests: sieve and hydrometer tests, Atterberg Limits, compaction, free swell and swell pressure. All direct and indirect methods mentioned in this paper indicated that the natural soil presented high to very high degree of expansion, which reached approximately $20 \%$ of free swell and nearly $200 \mathrm{kPa}$ of swell pressure. In order to evaluate the effect of lime, the same tests were conducted in soil-lime mixtures, using lime contents of $3 \%, 6 \%$ and $9 \%$. The results confirmed the efficiency of lime stabilization. It was noted that, as lime content increased, there was reduction of clay fraction and increment of silt fraction; plasticity index decreased to nearly its half; compaction curve was displaced; and free swell and swell pressure reduced significantly.
\end{abstract}

\section{Introduction}

Expansive soils are recognized by great changes in volume (swell and shrinkage), under same state of stress, upon variations in water content. They are widespread throughout world, especially in semi-arid areas, where climate has significant impact.

They can cause many structural and aesthetic problems to civil constructions, such as roads, airports, underground utilities, lightweight residential buildings and other facilities. In terms of economical loss, damages caused by expansive soils exceed the combined average annual damages from floods, hurricanes, earthquakes and tornadoes [1].

In order to enable construction of lightweight structures on top of expansive soils, special attention must be given to geotechnical designs. Foundations whose superstructures may be isolated from effects of expansive soils (e.g. pier and grade beam support), or foundations rigid enough to resist differential movement without causing damages to their superstructure (e.g. posttensioned slab-on-grade), should be selected.

Other alternative is soil stabilization. The treatment may be chemical, by adding products such as lime, cement and fly ashes, or mechanical, through addition of fibres.

Lime stabilization has proved to be one of the most efficient techniques used to mitigate swell potential. This paper intends to evaluate the effects on geotechnical

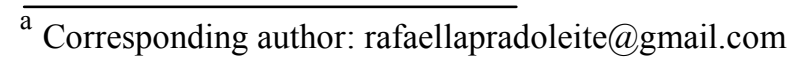

properties of an expansive soil collected in Northeast of Brazil, after mixed with selected percentages of lime.

\section{Literature Review}

Clay particles are characterized by negative charges on their plates, caused by isomorphic substitutions. In order to balance these charges, cations are attracted to their surface and are surrounded by polar molecules of water, which form a diffuse double layer, leading to expansion.

Montmorillonite is the most unstable clay mineral, since it presents higher amount of isomorphic substitutions and intercrystalline expansion.

Beside type and content of clays, many intrinsic and external factors may affect swell potential of expansive soil, such as dry unit weight, plasticity, initial water content, climate and surcharge loading.

There are several indirect methods to predict swell potential. They usually classify soils as having low, medium, high or very high swell potential. Some of them are charts based on soil activity $[2,3]$. Other methods include ranges of clay content and plasticity index [1].

\subsection{Lime Stabilization}

Stabilizing expansive soil by adding lime is an ancient art and an age old practice, which has been followed all over the world [4]. 
The short-term phase of lime stabilization is characterized by cationic exchanges: the addition of lime to clayey soils provides an abundance of calcium and magnesium ions, which tend to displace other common monovalent cations, such as sodium and potassium present on clay mineral plates [5]. This leads to a reduction of diffuse double layer water thickness which surrounds soil particles.

After cationic exchanges occur, several differences on geotechnical properties are expected. Increment of optimum water content and decrease in maximum dry unit weight of soil by adding lime was observed in several researches [5-8]. Reductions in clayey fraction and increase in percentage of silt due to aggregation and flocculation have been incontestably verified [7-9]. Decrease of plasticity index was also proven [6-8]. However, behaviours of plastic limit and liquid limit themselves may vary depending on type of soil. Both free swell and swell pressure have typically been reduced [59]. Nonetheless, low contents of lime may not be able to induce great reactivity, leading to reverse effects [7].

In addition, previous studies have shown that lime content and curing time of soil-lime mixtures have important effect on swell potential of soil [5].

\section{Materials and Methods}

\subsection{Materials}

The sample of soil used in this research is known as "massapê", recognized by its typical expansive properties. It was extracted in Nossa Senhora do Socorro, in the state of Sergipe (Northeast of Brazil). Since the sample was collected during the raining period, it did not show resistance to excavation.

Hydrated lime CH-I was used due to its high availability in Sergipe (this type of lime is classified according to chemical and physical properties proposed by Brazilian standard NBR 7175).

Lime contents of $3 \%, 6 \%$ and $9 \%$ were selected.

\subsection{Methods}

All tests were performed seven days after the mixture, allowing lime to react and cation exchanges to occur. It is important to highlight that, due to the need of removing the time factor from the variables, homogeneity of samples was a little compromised.

All tests were performed at least twice for each lime content, in order to enhance their reliability.

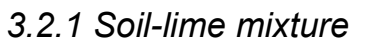

The amount of lime mixed with natural soil was based on the selected lime contents, which were related to the dry mass of pure soil. The mixtures were performed manually, and they were kept in plastic bags during a seven-day curing period.

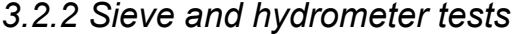

Sieve and hydrometer tests were performed in order to obtain grain size distributions of natural soil and soil-lime mixtures. The procedures of this test followed the recommendations indicated by Brazilian Standard NBR 7181.

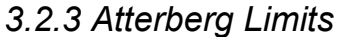

Liquid limit, plastic limit and shrinkage limit tests were performed following the procedures indicated by Brazilian Standards NBR 6459, NBR 7180 and DNERME 087/94, respectively.

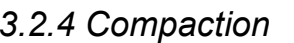

Compaction tests were performed following the recommendations in Brazilian Standard NBR 7182. Standard Proctor Energy was applied and the small mould was selected. These tests had the goal of providing the parameters of compaction for free swell and swell pressure remoulded samples.

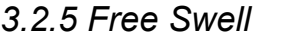

These tests followed the procedures indicated by ASTM D 4546-03. Method A was selected for their performance. At first, the specimen was moulded with water content and dry unit weight similar to the parameters obtained from compaction curves. Later, the sample was placed in a consolidometer apparatus, under a seating pressure of at least $1 \mathrm{kPa}$. Within 5 minutes, the extensometer device was adjusted and the specimen was inundated from top and bottom and allowed to swell vertically.

Deformation readings were made typically at $0.1,0.2$, $0.5,1.0,2.0,4.0,8.0,15.0$ and 30.0 minutes and $1,2,4$, $6,24,48$ and 72 hours, until invariability was achieved, after primary and secondary swell. Then, the percent of free swell was related to the specimen's initial height.

Preparation of specimens is shown in Figure 1.

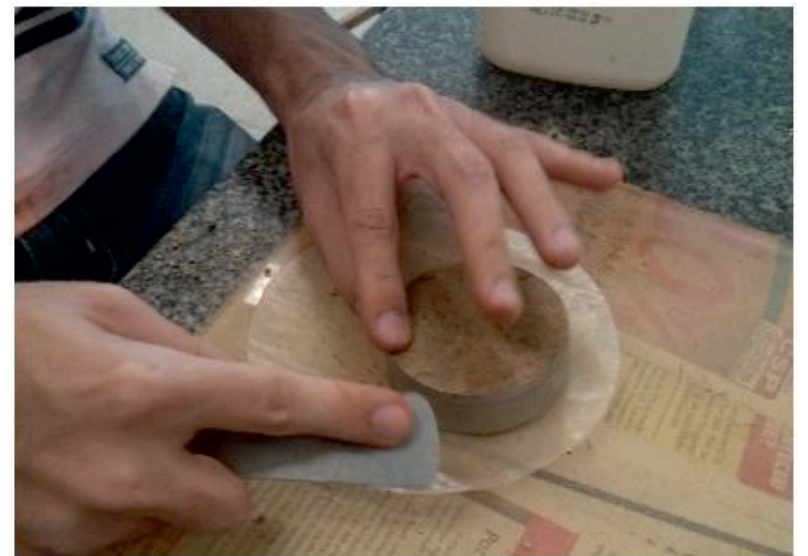

Figure 1. Moulding of specimens for Free Swell and Swell Pressure tests. 


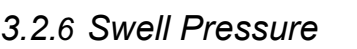

Swell pressure tests had similar procedures to free $₫$ swell tests. After primary swell was achieved, vertical pressure was applied in increments on the top of the specimen, until initial void ratio was reached, i.e., no swell was registered by the extensometer.

Placement of specimen in a consolidometer apparatus and load increments are shown in Figure 2.

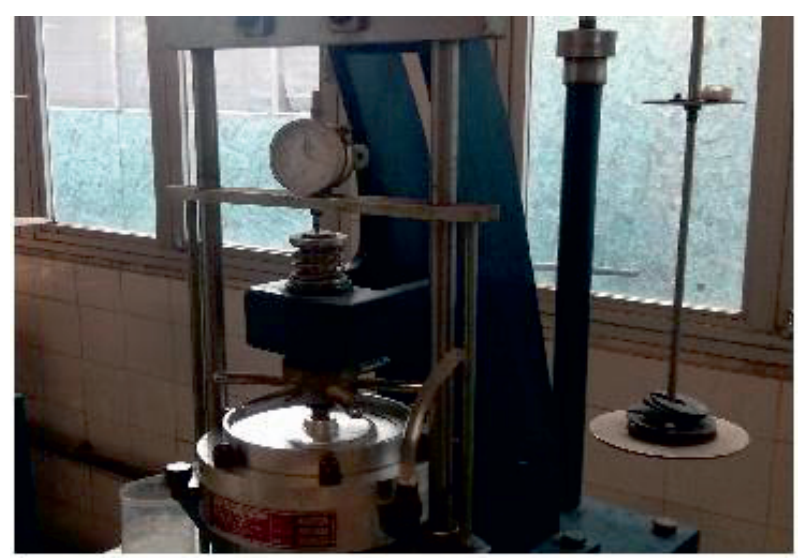

Figure 2. Swell Pressure Test.

\section{Results and Discussion}

\subsection{Natural Soil Characterization}

Sieves and hydrometer tests performed on natural soil revealed predominance of fine-grained particles (approximately 94\% was finer than sieve \#200) and clay content around 38\%. Grain size distribution is shown in Table 1, considering MIT classification.

Liquid limit and plastic limit values of natural soil were 57 and 23, respectively, which results in a plasticity index of 34.

Indirect methods [1-3] predicted natural soil to present high to very high degree of expansion.

Table 1. Grain Size Distribution of Natural Soil.

\begin{tabular}{|c|c|c|}
\hline Classification & Grain Size & \% \\
\hline Gravel & $2 \mathrm{~mm}-6$ in & 1.8 \\
\hline Sand & $60 \mu \mathrm{m}-2 \mathrm{~mm}$ & 13.2 \\
\hline Silt & $2 \mu \mathrm{m}-60 \mu \mathrm{m}$ & 47.2 \\
\hline Clay & $<2 \mu \mathrm{m}$ & 37.8 \\
\hline
\end{tabular}

\subsection{Hydrometer and sieves tests}

Grain size distribution of natural soil and soil-lime mixtures are shown in Figure 3. The results show significant decrease in clay fraction and increment of silt fraction when lime was added, in accordance with previous studies. Sand fraction increased slightly.
This behaviour can be justified by the aggregation and flocculation of soil particles, due to cationic exchanges induced by lime treatment.

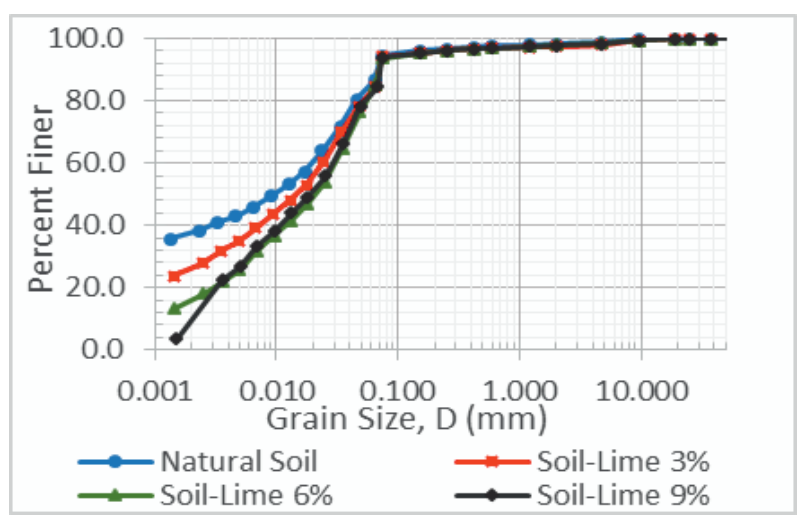

Figure 3. Grain Size Distribution Curves.

\subsection{Atterberg Limits}

The results of Atterberg Limits from natural soil and soillime mixtures are given in Figure 4.

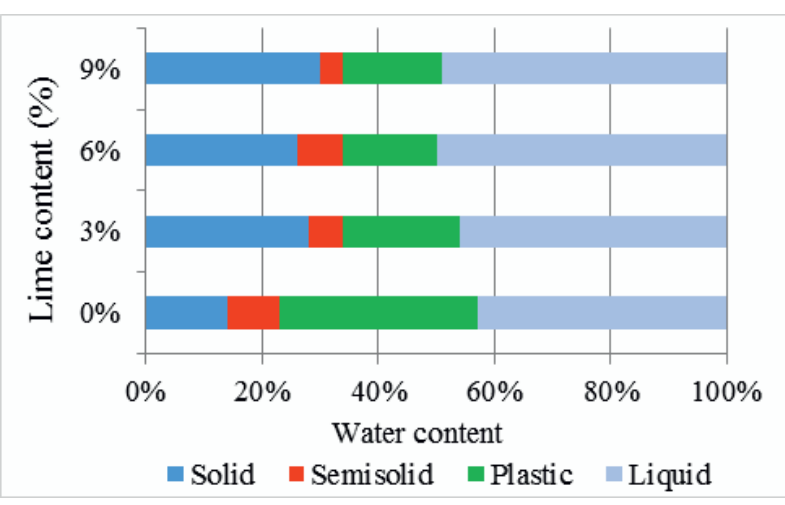

Figure 4. Atterberg Limits Results.

As expected, plasticity index decreased significantly (to nearly its half) when lime was added. There was a slight decrease in liquid limit, whereas plastic limits increased substantially when $3 \%$ of lime was mixed. However, higher contents of lime had almost no additional effect on plastic limit and plasticity index.

The reduction of soil plasticity also leads to an improvement of soil workability.

Besides, an increment of shrinkage limit can be noticed, leading to a smaller range of water content in which cracks and fissures are formed.

\subsection{Soil Classification}

According to Unified Soil Classification System, this expansive soil can be classified as a clay of high plasticity $(\mathrm{CH})$, since its liquid limit is higher than 50 and it is situated above the line A from Casagrande's Plasticity Chart. Due to reduction of Plasticity Index, the addition of lime turned the pure soil into a highly compressible silt, for all contents used. This difference can be visualized in Figure 5. 


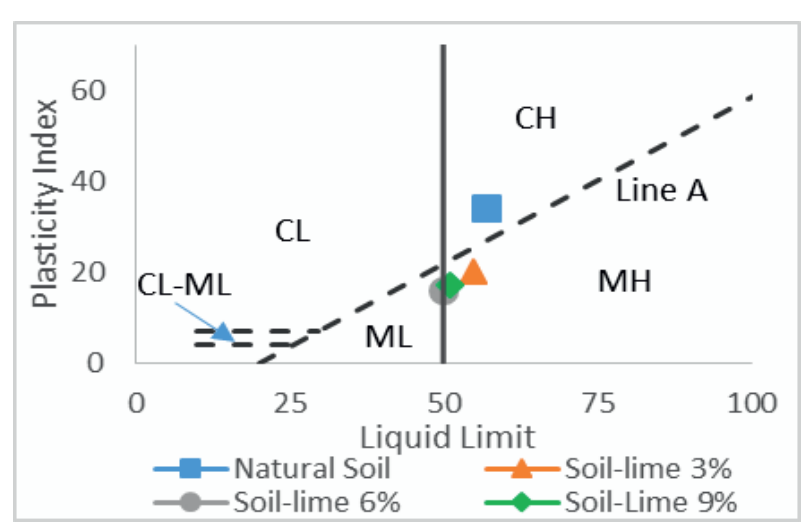

Figure 5. Classification of natural soil and soil-lime mixtures.

\subsection{Compaction}

The results of compaction tests performed on natural soil and soil-lime mixtures can be visualized in Figure 6.

In accordance with literature, the results show that there was reduction in maximum dry unit weight and increment of optimum water content, proportionally to the lime percentage added. Optimum water content increased from $17.9 \%$ up to $21.2 \%$, and maximum dry unit weight varied in the range of $16.87 \mathrm{kN} / \mathrm{m}^{3}$ to 15.90 $\mathrm{kN} / \mathrm{m}^{3}$.

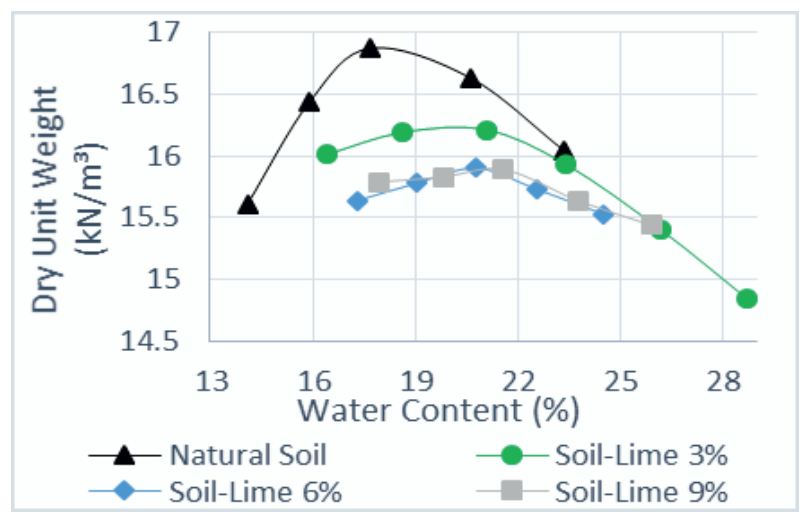

Figure 6. Compaction Results.

This behaviour can be explained by the flocculation induced by adding lime. Initial void ratio increases, and the soil fabric is strong enough to resist the same Proctor energy, reducing the maximum dry unit weight of the mixture. In addition, higher volume of voids requires larger amount of water to be fulfilled, raising the optimum water content.

It is also possible to observe that compaction curves tend to reduce their concavity as lime is added, which leads to lower sensitivity from changes in moisture.

\subsection{Free Swell}

The final results of all free swell tests performed on natural soil and soil-lime mixtures at seven-day cure time are shown in Figure 7. As mentioned in literature, swell potential reduces significantly when lime is mixed with expansive soil. It can be noted that by adding $3 \%$ of lime, the percentage of swell decreased from $20 \%$ to approximately $1.85 \%$. Lime contents of $6 \%$ and $9 \%$ presented free swell close to $1.0 \%$ and $0.5 \%$, respectively, which are below the brazilian imposed limits for pavement subgrades and base.

The tests performed on natural soil took six days to be completed. On the other hand, the final results from soillime mixtures were achieved after only 2 days, which probably indicates that addition of lime also affects permeability of soil.

In Figure 7, we can also observe that the results from both samples of each lime content are quite similar, diverging up to $10 \%$ approximately.

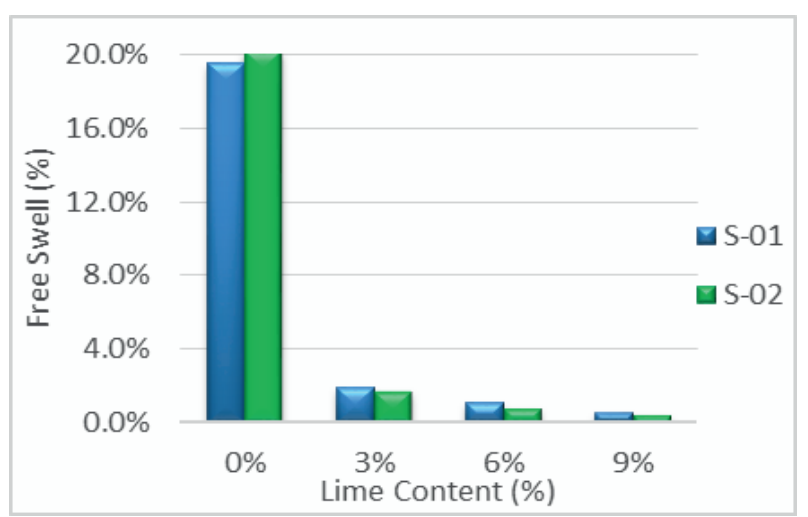

Figure 7. Free Swell Results.

\subsection{Swell Pressure}

The final results of all swell pressure tests performed on natural soil and soil-lime mixtures at seven-day cure time are given in Figure 8.

As expected, there was significant reduction in swell pressure due to lime treatment. The addition of only $3 \%$ of this chemical stabilizer reduced swell pressure from nearly $200 \mathrm{kPa}$ to an average value of 37 . Lime contents of $6 \%$ and $9 \%$ presented mean swell pressures of $32 \mathrm{kPa}$ and $23 \mathrm{kPa}$, respectively.

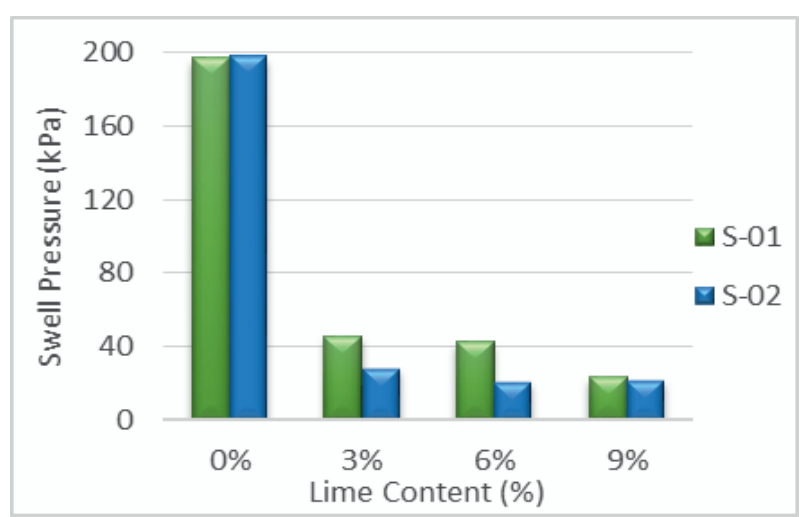

Figure 8. Swell Pressure Results.

The most accepted reason to explain this behaviour is the decrease in maximum dry unit weight by adding lime, which causes weaker repulsion forces between the particles of soil [7].

The results from both tests of soil-lime mixtures of $3 \%$ and $6 \%$ presented small discrepancy. It could be caused by inaccuracies from the test itself; by small differences in compaction parameters when moulding the 
samples; or by the loss of homogeneity induced by the need to assure the same curing time for all samples. However, these differences are not significant enough to modify the conclusions obtained from these tests.

\section{Conclusions}

Due to cationic exchanges, which lead to agglomeration and flocculation of soil, lime stabilization causes significant effects in many properties of expansive soils, such as:

1. Reduction of clay fraction and increase of silt and sand fractions;

2. Plasticity index of soil reduced significantly by adding lime, due to a slight decrease in liquid limit and to an expressive increment of plastic limit.

3. Compaction curves were displaced. By mixing lime and natural soil, optimum water content increased and maximum dry unit weight decreased.

4. Addition of lime caused drastic reduction on swell potential. Free swell reduced from $20 \%$ to $1.85 \%, 1.0 \%$ and $0.5 \%$. Meanwhile, swell pressure decreased from $200 \mathrm{kPa}$ to $37 \mathrm{kPa}, 32$ $\mathrm{kPa}$ and $23 \mathrm{kPa}$, when $3 \%, 6 \%$ and $9 \%$ of lime were blended, respectively.

\section{References}

1. F. H. Chen, Foundation on Expansive Soils (Elsevier Scientific Publishing Co., New York, 1975)

2. H. Seed, R. J. Woodward Jr., R. Lundgren, ASCE, 88, 53-88 (1962)

3. D. H. Van der Merwe, Trans. SA Ins. Civ. Eng, 6, 103-107 (1964)

4. S. Bhuvaneshwari, R. G. Robinson, S. R. Gandhi, IGJ, 44, 278-293 (2014)

5. A. R. Estabragh, H. Rafatjo, A. A. Javadi, Geosynth Int, 21, 233-243 (2014)

6. J. J. J. M. Garcia, Masters Thesis - Universidade Federal do Rio de Janeiro (1973)

7. $\square$ M. A. M. Silva Júnior, RBGEA, 2, 2 (2012)

8. $\square$ A. L. I. K. Abass, JEAD, 17, 1 (2013)

9. V. Barbosa, Masters Thesis - Universidade Federal de Pernambuco (2013) 